\author{
MAGDALENA ŻARDECKA* \\ ORCID: 0000-0003-3581-6424
}

\title{
SOCIAL STRUCTURE AND COLLECTIVE MEMORY
}

Keywords: social theory, structuration, collective memory, unconscious Słowa kluczowe: teoria społeczna, strukturacja, pamięć zbiorowa, nieświadomość

Philosophical considerations concerning collective memory usually focus on the question of customs, traditions, sites of memory and/or the sense of identity - much less often on social structure and on dynamics of change. And yet connections of structure and social/cultural dynamics to the

* Magdalena Żardecka - specializes in contemporary philosophy, social philosophy, philosophy of politics and philosophy of culture. Author of the books: Wspólnota $i$ ironia. Richard Rorty i jego wizja spoleczeństwa liberalnego (Commonwealth and irony. Richard Rorty's vision of liberal society - Lublin: Wydawnictwo KUL, 2003), Rozum i obywatel. Idea rozumu publicznego oraz koncepcja jednostki we wspótczesnej filozofii polityki (Reason and citizenship. The idea of public reason and conception of the individual in contemporary philosophy of politics - Rzeszów: Wydawnictwo Uniwersytetu Rzeszowskiego, 2007), Pamięć i zapomnienie. Filozoficzny dyskurs o sile i słabości pamięci indywidualnej i zbiorowej (Memory and oblivion. A philosophical discourse on strength and weakness of individual and collective memory - Rzeszów: Wydawnictwo Uniwersytetu Rzeszowskiego, 2020).

Address for correspondence: University of Rzeszów, Institute of Philosophy, Rejtana 16C, 35-959 Rzeszów, Poland. E-mail: magda.zardecka@gmail.com. 
phenomenon of memory are equally patent, and maybe even more basic and fundamental. In this text I am going to address the phenomenon of collective memory as a source of social structure or structures and of social diversity, as well as a condition of possible social change.

\section{Maurice Halbwachs: social structure, prestige and covering up the traces of change}

Concepts of collective memory and of social/cultural structure are complex and do not easily yield to attempts of definition. For the purposes of present analysis I shall assume the supposition implied by Halbwachs's texts that collective memory is a social frame which makes possible for the individual thought to reach to the past events and to recapture memories (Halbwachs, 1992, p. 38); it is a frame in which the past has a chance to reappear. Collective frames of memory are neither constructs built of combinations of individual memories nor forms, into which these individual memories are somehow squashed or forced. They are "the instruments, used by the collective memory to reconstruct an image of the past which is in accord, in each epoch, with the predominant thought of the society" (Halbwachs, 1992, p. 40). An individual who recollects the past has no other choice as to assume the point of view of the group; the memory of the group, in turn, is realized and manifests itself in memories of individuals.

No society is entirely unified and egalitarian; every society is featured by diversification and stratification in virtue of prestige, competences, birth, wealth, achievements, dignity, power, etc. Representatives of various social strata (classes) differ among themselves in respect to life chances and possibilities, access to various goods, ways of life, consumption models, acknowledged hierarchy of values, ways of acting in the world and relating to others and so on. Social strata (classes) are related to each other hierarchically (systems of ranks), but the fact of belonging to them cannot be definitive and unambiguous, and they themselves cannot be treated as disjoint sets, because the processes of composition and decomposition of such identities are constant and ongoing. Stratification, supported by myths, rituals, laws and habitus, is the result of ongoing, long-term processes which members of a given society were not able to notice and follow consciously - firstly, because of their duration (exceeding the lifetime of an individual), secondly, 
because no social actor was able to assume towards them the position of an observer during their occurrence - so social actors couldn't preserve them in their memory in the form of concrete recollections (semantic memory), even if it could be possible for them to recollect post factum some events that, with a considerable amount of mnemonic and intellectual effort (reminiscing), would contribute to the more or less coherent picture of changes undergoing in the surrounding world and in themselves or would give an answer to the question about causes of social diversification. Long-term processes escape the notice of individuals absorbed with the current course of life, with the care of their own economic condition and social status, but do not turn into nothing; they endure as something that decides about the shape and form of a given society. The past is vividly present in the now in the form of social structure, obvious to all members of the society, as well as in the form of explicitly unexpressed, "intuitively" recognizable and applied principles of life (different from explicitly formulated rules of law), which, on closer examination, turn out to be an aspect of condensed memory, recreated and reenacted in subsequent exposures and repetitions. Just as the body of an individual unwittingly repeats lessons learned in youth (motor memory: mastering various principles, skills and dexterity), so the social body reenacts the lessons taken from history, placing individuals in a certain structure and disposing them to certain kinds of behavior (habitus, hexis), in a way irrespective of, and sometimes even in spite of their conscious efforts. The structure is thus something that, dividing and diversifying, simultaneously shapes and integrates actions of individuals, groups and institutions.

Halbwachs, who was first to make an attempt to describe mechanisms of functioning for this kind of memory, pointed to differences in formation of human behavior in periods of stabilization and in times of breakthroughs, changes and revolutions. In periods of stabilization social structure appears to members of a given society as unproblematic and obvious, nobody remembers about contingent, historical sources of social differentiation. Things are different, however, in times of breakthroughs. Halbwachs gives an example of the 17. and of the 18 . century. At the beginning of this period there was a strong conviction that aristocrats represent a higher human category "in that they could point to ancestors who had proved their mettle, who had perpetuated and renewed a set of physical and spiritual properties transmitted through inheritance that enhanced the personal value of their members" (Halbwachs, 1992, p. 126). This conviction of superiority of the noble state 
persisted in spite of the fact that nobility of that time was in a rather poor shape, decimated by wars, ruined financially and unable to accommodate to the new epoch. Because of their indolence, many a monarch was forced to base the growing bureaucratic machinery of state on educated bourgeoisie. This fact, however, was concealed in various ways to avoid offending nobility, challenging established presumptions concerning this privileged group, putting on trial loyalty of the subjects and compromising monarchial authority. So monarchs kept up appearances, pretending to still rely on the nobility's traditional prestige, while surreptitiously entrusting more and more tasks to bourgeoisie. In the next step, however, they confirmed the promotion of the bourgeois through the act of ennoblement. Hence so great an increase of fresh noblemen in this period.

Rich and educated bourgeoisie, in order to exercise honorable functions, to sit in counsels, courts and offices, was obliged to install in nobiliary castles, to acquire nobiliary shields and to buy titles. This is how upon the former, older structure has been grafted a new one, legitimizing itself through taking the appearance of its precedent. Halbwachs underscores that "[a] society does not proceed from one organizational structure to another through the conscious effort of its members, as if they build new institutions in order to reap actual advantages from their efforts. How could they know such advantages before these institutions had begun to function precisely in their own group?" (Halbwachs, 1992, p. 121). It is only by means of a sequence of invisible acts of retouching, consisting in introducing the new beneath the mask of the old, that, in the due course of time, a new form of institution has been shaped, which then could be admitted "immediately" as a well known structure, uncontroversial and in accordance with tradition. This example shows how new institutions emerge from indefinite areas of social mist, appearing in collective consciousness only after a longer period of perduring outside it or on its margins. The fact of their acceptance does not result from clear understanding of their utility - this simple logic does not function in social life. They have to grow old, blending with traditions that they are supposed to replace (Halbwachs, 1992, p. 125). Only the respect to the past and to memory can justify them in the eyes of the citizens, because society grants its acceptance and recognition only on the basis of its memories, and not on the basis of its reasonable calculations and settings. New techniques of governance can emerge only while maintaining appearances of tradition and under cover of old external forms. 
It is for a long time that nobility described by Halbwachs still enjoyed respect and held usual honorable functions, continuing to perform ritual gestures, to wave their pennons, to wear their insignia, to spout pompous formulas and to perform ceremonies. And yet from their prerogatives were slowly and quietly exempted bureaucracy and technical skills, gradually entrusted to lawyers, officials, military, engineers etc. It is them who now overtook the duty of caring for social integrity, for the strength of the state, for economic development, for internal order, or even for the efficiency of military actions - because all this was presented as "prosaic, mundane activities" that do not require noble qualities. People performing these tasks were identified with their profession or function and evaluated according to the quality and efficiency of their work - a similar treatment would be unthinkable in reference to aristocrats.

What counted in the world of aristocracy of the 17. and of the 18. century were still honors and titles, impossible to measure and define in any abstract way. ${ }^{1}$ A particular nobleman's position is based on antiquity of his title. To be able to estimate it, one has to know the whole complex history of his family and house, for in nobility the present is intertwined with the past. "We deal here with relationships not only among individuals (which might be understood in a semiphysical and technical sense) but among groups and social values. A value of this kind consists in a series of judgments resulting from an association of thoughts that - like all other states of consciousness which are a little complex - need some time to become established and presented as remembrances no less than as present states" (Halbwachs, 1992, p. 129).

Until the 19. century aristocracy remains a group responsible for conserving memory and sustaining tradition. Yet since the 18. century arise slowly "new traditions", exempted from aristocratic control. A particular form of these "traditions", emerging in this period, is the collective memory of professional groups - something that Halbwachs calls "corporate spirit". "Such a sensibility is formed and fortified from age to age because the function which supports it has itself been active for a long time, and because

${ }^{1}$ As Halbwachs writes, , in the nobility, through the generations there continues a totality of well-linked traditions and remembrances. Since there is nothing similar in other groups, it must be said that the noble class has for a long time been the chief upholder of collective memory. To be sure, its history is not the complete history of the nation. But nowhere else is found such continuity of life and thought, nor is the rank of a family so clearly defined by what it and others know of its past" (Halbwachs 1992, p. 128). 
the people who exercise it are in frequent contact in that they accomplish the same operations or in any case are engaged in operations of the same nature so that they have the perennial feeling that their activities are combined with a view to a common undertaking. But, at the same time, what brings them nearer to each other is the fact that their function can be distinguished from other functions of the social body. It is important for them, and in the interest of their profession, to emphasize these differences and make them clearly visible" (Halbwachs, 1992, p. 139). To accentuate the distance separating them from other groups, judges wear distinct robes, occupy distinctive places in courtrooms, their speeches are pompous and formalized, their dialogues with plaintiffs and defendants take the form of interrogation, their reasoning is imbued with history of law and precedents. Judges create distance and carefully maintain it. Other professional groups follow their example. "If we call collective memory that totality of traditions pertaining to a body of functionaries, we will conclude that there are at least as many collective memories as there are functions, and that each one of these memories is formed within each of these groups of functionaries, through the simple play of the professional activity" (Halbwachs, 1992, p. 141). In the professional world, however, everything is part of a recently constructed apparatus, deprived of history and tradition. Nobody asks an official about the past of his family, or even since when he is exercising his office. What comes to the fore is a new, pedantic, procedural, formalistic attitude of mind, an attitude that does not inquire into genealogy, does not care about history and does not look for depth, but focuses on efficiency of the actual action.

People represent various professions, but above all are members of their families and peer groups. It is there where, according to Halbwachs, flows the main stream of social life; it is there where ripen the key ideas, attitudes, opinions and assessments that subsequently spread in the society, imbuing other groups. People abiding in families and/or among friends are deeply influenced by these groups; coming back to their workplaces, they carry ideas, points of view and whole evaluation systems elaborated and ripened therein. In these root milieus there is, as it was once the case among nobility, no hierarchy of titles; what matters, instead, is the constant effort of maintaining a specific spiritual attitude, of passing on traditions, derived from culture. Bourgeois collective memory does not certainly have the depth of the aristocratic memory (since it does not have this kind of history), but we may say that it has a wider range instead. What counts here is also prestige that is 
an equivalent of the series of memories concerning a given individual (just as honor was an equivalent of genealogy of a given aristocrat). Society treats the rich with respect not because of their very wealth, but because of their supposed traits of character (diligence, resourcefulness, energy, continence, neatness, thriftiness, reliability), indispensable in acquiring it. The nouveaux riches or those who have acquired their wealth all too easily are treated with great suspicion.

Halbwachs underlines that although in the synchronic view society seems to have a stable structure, in reality it is never held captive in immutable forms. Quite on the contrary - it changes constantly, adapting to all kinds of alterations. In social life one has to take into account an almost infinite number of historically variable factors: origins, education, influence, milieu, social position, profession, fits of bad temper, play of passion, ambiguity of words and many other various circumstances. We are able to understand the surrounding reality only because we are members of a given society who have their share in the vast zone of personal relations, "in which society does not limit its horizon, for it is not concerned with accomplishing a function, but only with fortifying in each of its members the awareness of his social rank, or of intensifying collective life" (Halbwachs, 1992, p. 163).

Pierre Bourdieu: contemporary problematization of the hiding maneuver

The view that social structure and diversification is a form of memory, presenting itself as an ahistorical self-evidence, represents also Pierre Bourdieu. This author, in his numerous works, undertakes an unprecedented effort of anamnestic recognition of sources of various self-evidences and inhibitions of our social life (socioanalysis) (Bourdieu, Wacquant, 1992a, 1992b). Differences between practices, habitus, posessed goods and expressed opinions form, according to him, a real symbolical system, a language we have to learn. Inner worlds of individuals are a result of interiorization of the structures of the social world. Existence in society, just like existence in language, consists in differing. Difference is a sign and a distinction, when we understand it from the point of view of principles of perception and of divisions holding for a given group (Bourdieu, 1998, pp. 7-9). Social space is 
a kind of an invisible sphere, intouchable and inperspicable from outside, and yet the most real, for it organizes the ideas of individuals and allows, with great probability, to predict their behavior. One of regularities is the rule that people who are situated in the upper stratum of this space have little chances to get in touch with those who are situated it its lower parts, and when they accidentally happen to meet them, they are unable to hear them and to understand their words and actions (Bourdieu, 1998, pp. 10-11).

Bourdieu stresses that his intention is not to define social classes, united by the common interest and antagonistic towards others in Marxist sense, and even less to substantialize such classes. He opposes as well such descriptions of the society that deny existing of differences and stress the process of homogenization and democratization (Bourdieu, 1998, pp. 1113). To put an end to the discussion on existence of social classes, he uses the concept of social space, allowing to grasp the fact of social differentiation that underlies various actions, confrontations and antagonisms between individuals (agents), without, however, imposing a vision of society as a system - a coherent whole, bound by precisely defined functions (Bourdieu, 1998, pp. 31-32). The social space is conceived as a dynamic field of forces, perceived by agents as necessities; it is a constantly reproduced sphere of differences (governed by the principle of differentiation) that "is indeed the first and last reality, since it still commends the representations that the social agents can have of it" (Bourdieu, 1998, p. 13). The principle of differentiation underlies the structure of distribution of capitals of all kinds - be it economic, cultural, social, political or symbolic - in the social universe.

The cultural capital which, together with the economic capital, is according to Bourdieu the basic factor of social differentiation, could be accurately described in a way proposed by Halbwachs as group memory this issue would be worth a separate study. It seems that such a description would not distort the thought of Bourdieu, all the more that he emphasized the diachronic (historical) character of all social phenomena that sociology synchronizes to the detriment of their understanding.

Part of the cultural capital can be described as educational capital. Keeping up appearances of the equality of chances, schools form, according to Bourdieu, a huge sorting machine (Maxwell's demon), separating children from families with a large cultural capital at their disposal from children stemming from families with a small capital in order to place the former in better academic institutions and finally to position them in higher professional 
ranks, usually unavailable to the latter. Consequently, the system of differences is maintained, in spite of its official abolishment. Schools repeat and reproduce social memory, not only caring about transmitting certain programmatic contents, but also permanently restoring the social structure and constantly justifying it. This justification consists in rationalization that cannot be denied: students who did not obtain good results in schools and who ended up with unattractive jobs can only blame themselves, the competences of beneficiaries of the system are indisputable for all (Bourdieu, 1998, pp. 20-22). Bourdieu states sarcastically that former noble titles did not vanish at all, but have been transformed in academic titles. Under the external cover of democratic liberties and equality a new hereditary nobility was born, consisting of company owners, physicians, high rank official and political leaders (Bourdieu underscores that this process took place not only in the French society, studied by him for many years, but also in other European countries and, e.g., in Japan - so we can suspect that this phenomenon is universal in character). Traits and skills awarded in the educational process have served as pretext for maintaining traditional, hereditary privileges (this mechanism confirms two myths that fundamentally oppose each other: the democratic myth and the myth of destiny, but actually nobody notices this opposition). What has been concealed from view of the society was the combination of the so called learning abilities with the cultural capital received at home (repression). The contemporary state ability enjoys its authority resulting from academic titles; the privilege of being well-born has been transformed into the privilege of being well-educated, confirmed by excellent schools. "A review of history suffices to reveal that the reign of this specific nobility, in France and no doubt in Japan as well, is a corporate body which, created in the course of the state's creation, had indeed to create the state in order to create itself as holder of a legitimate monopoly on state power" (Bourdieu, 1998, p. 22). Invention of the state, of the public sphere, of the common good and of the public service has strengthened the power of those who anyway already had exercised that power long since. Therein consists determinism of the social life, criticised by many authors. 


\section{Alain Touraine: A contrastive case of theoretic annulment of memory}

A keen debater and opponent of Bourdieu was Alain Touraine, the founder of the sociology of action and of the theory of self-production of society. He denounces the static character and the fatalism of Bourdieu's structural constructivism, where the individuals appear as totally enslaved by the given, preestablished structures and by the discourse of the dominant class (the logic of domination). Touraine emphasizes that society acts upon itself in the constant process of self-production, enabled by historicity. The social life should not be seen exclusively in functional or structural, in economic or institutional terms; social theorists should not focus uniquely on the hidden sources of domination, inequality and exclusion (the end of the era of suspicion) - they ought to be viewed in reference to culture and personality. The social order according to Touraine is not based on some system of norms and values that would be external to it (rejection of determinism, of laws of functioning, of ideas imposed from outside, of the divine law, of the meaning of history, etc.). The efficiency of power manifests itself in the ability to shape behavior and to create personality that opposes power (empowerment, subjectification, liberty). The social world is produced by the action of a collective subject who, transcending individual consciousness, creates values and controls cultural models. Historicity consists in the process of self-constitution of the society, who creates itself, deriving from its own resources. Thanks to historicity the society takes distance from itself and is able to act with a great amount of liberty, determining its own practice (self-production of society, ability to create one's own social and cultural orientations). At the same time historicity is, according to Touraine, the highest level of the analysis of social systems of action, the most general instrument of studying and describing societies. Touraine supposes that there exists a constant tension between historicity and functioning of the society, between being and becoming, and that this tension decides about the ability of a given society to transform itself and to influence the character of social relations. Social action is a collective effort of constant production of objects and of endowing them with meaning (creative work). The main dimensions of historicity are the model of knowledge, accumulation and the cultural model. The model of knowledge is a particular relation to nature, 
accumulation is the ability to invest surpluses in the process of change of social relations, the cultural model is a way of grasping of the two former forms of reflexive action of the society upon itself in the form of a certain representation, that is, of a collective image that orients social transformative actions. Historicity develops through a system of action that is the common oeuvre of actors of historicity, creating specifically understood social classes.

Let us notice that, although Touraine made of historicity and system of historical action the two key concepts of his theory, it is difficult to find in his works any reference to relations between society and its own past and memory. Historicity turns out to have nothing in common with the past. This notion points to the ability of the society to transcend itself through the constant motion of projecting itself into the future, drawing on its own resources, rational decisions, contracts and imagination (creating objects and endowing them with meaning) (Touraine, 1977, pp. 15-64) The past and memory, the two dimensions almost never mentioned by Touraine, constitute only something that should be overcome and nullified. In order to understand the present, the society does not turn to its past, but turns its eyes to the future, relying on innovation. The past is only a negative point of reference: tradition means inertia and reproduction. We have to do here unquestionably with the Sartrean way of thinking and acting, totally engaged in prospection, understanding freedom as ostentatious and constant rejection of the past and projecting oneself into the future. Explanations of actions without precedent in former social practice have to refer to transactions that are associative, imaginative, fancy and symbolizing in character (see Castoriadis, 1987). Memory is treated by Touraine neither as a source of social resources nor as a source of categories explaining the present state of affairs. The defender of democracy and freedom (labeling his sociology as knowledge in service of liberty) seems to be unaware of the fact that rejecting the past and memory, he exposes himself and the society to the danger of neurotic repetitions.

Anthony Giddens: A return to memory in analyses of social dynamics. The (Un)conscious

Anthony Giddens's theory of structuration, on the other hand, shows how individual actions are "situated" in everyday practices of social life, and 
how structural and organizational aspects of society are "reproduced" by individual actions. I propose to treat "situating" as well as "reproducing" as functions of social memory. Giddens, just as Touraine, emphasizes that society is not a constant, petrified form, but a living and changing stream of actions and interactions; it is characterized, for one thing, by inner dynamics, and for another, by durability and orderliness. Just as grammar rules allow people to build standard and non-standard utterances, so rules of social life allow them to act in different ways (without excluding their liberty, but also without encouraging them to use it). Individuals are not exclusively passive reproducers of social roles that have been instilled in them, but are (as well) subjects endowed with initiative and capacity of reflection (interpretation and negotiation of meanings). In every individual subject we may, according to Giddens, distinguish three levels of knowledge and motivation: discursive consciousness, practical consciousness, unconsciousness. Only the contents of discursive consciousness are subject to articulation. Basic dimensions constituting practical consciousness are knowledge and the ability to function in society - dimensions that the individual could not fully articulate under consideration (Giddens, 1984, p. xxiii), not to mention penetrating into the depths of her or his own unconscious. In the area of practical consciousness and unconsciousness we could place those dispositions and skills that Bourdieu referred to as habitus.

Structure in Giddens's understanding is equal to structuralizing properties, urging different members of society, in different times and subjectively for many reasons (on the level of discursive consciousness), to act and behave similarly (practical consciousness), as if they followed the same rules (unconsciousness). Structure, meaning in Giddens's theory "virtual order of transformative relations" (Giddens, 1984, p. 17), is something that on the one hand limits the set of possible actions, but on the other hand facilitates certain possibilities. Structure itself is a result of actions and a means, allowing them to attain their goals. Social structure exists only in the actions of individual subjects who are members of a given society and who comply with certain determined rules, but only on them depends whether these rules obtain or not. Rules exist as long as they obtain and prevail, that is, as long as they are applied in practices. Society not so much has structure, as exhibits certain structural properties; "structure exists, as time-space presence, only in its instantiations in such practices and as memory traces [underlining mine - M.Z.] orienting the conduct of knowledgeable human 
agents" (Giddens, 1984, p. 17). Structure is responsible for reflecting social relations of phenomena in time and space, for the reproduction of practices. These memory traces, "instantiated in social practices, are in certain sense more 'internal' than exterior to [actors'] activities in a Durkheimian sense" (Giddens, 1984, p. 25).

\section{Jan Assmann: Memory in conditions of growing complexity. Writing and counter-identity}

In complex cultures, embracing many different groups, there is always a problem of internal integration. The dominant culture, trying to ensure coherence, generates inequalities, divisions, or even social gaps. The factor that largely contributed to maintaining the social coherence, creating at the same time numerous new inequalities in civilized societies, was the invention of writing (Assmann, 2011, p. 128 f) On the example of ancient Egipt Jan Assmann shows how literate and educated group, then sparse, created a new, hitherto unknown kind of aristocracy that gradually strengthened its position and finally took over the power in the state. High culture became their exclusive domain; they agnized it for culture as such, for the medium of participation in humanity of a higher order (elitism). Writing became responsible for two seemingly opposite social processes: for integration (assimilation) of various groups inside society and for creation of hierarchies and social division.

In complex cultures there is always a strong tendency to distinguish minor groups - to differentiate among themselves as well as between them and the dominant totality. Assmann calls this phenomenon enhanced distinctiveness. Minority cultures do not turn in this case against external reality, understood as savage and inhuman, but against the dominant culture that menaces it. Distinctively enhanced identity is always a resistance movement and a "counter-identity" (Assmann, 2011, p. 134).

Distinctiveness is also a feature of exclusive elitist cultures. The upper spheres begin to attach great importance to manifesting their distinctness (in line with the principle noblesse oblige), they consciously cherish, stage and stylize their existence (elitism). In this way they strengthen and enforce their counter-identity in reference to the others, menacing them with their majority. Social structure and the sense of identity and distinctness is in every case a sort of compressed memory of a given group. 
Jeffrey Alexander: A synthesis. The project of cultural sociology as hermeneutics and social psychoanalysis

Another author who, studying the dynamics and the statics of societies, points to their strong bond with what Halbwachs called collective frames of memory, is Jeffrey Alexander. Social actors, having at their disposal certain (limited) resources of time, energy and knowledge, are always able to influence their external situation. Ethnomethodology, an important point of reference in Alexander's theory, explaining human activity as acts aiming at creating order, showed that continuity and durability of cultural patterns is based on uninterrupted action of what Husserl referred to as transcendental traits of human consciousness. These traits appear in Alexander's theory not as ahistorical and transcendental, but as a "compressed" group memory. Human consciousness has an inclination to make each mental impression fit into, i.e to make it part of the horizon that preceded it (i. e., memory) (Alexander, 1988, p. 310). In the process of socialization we acquire a habit of transforming (wittingly or unwittingly) that what is new in that what is old. It is what our capacity of typization consists in. But all that routine and conformism, which inevitably become part of our experience, all motives and cultural patterns, norms, values and social roles that we assimilate do not mean that we entirely and irrevocably lose our freedom and invention. The reality that confronts our contingency usually appears to us the same as what we formerly had to do with, we have towards it certain defined expectations, we assume that it is just another "example of the past"; yet what is given to us here and now never really allows itself to be exhausted in similitude to that what already has been, but always is also something more, bears in itself an element of surprise, of genuine mystery (Alexander, 1988, p. 313). Even if we assume that the future will be just the same as the past, yet at the same time we forefeel, suppose and imagine that it can be entirely different. That is why we have to enrich every typization with our invention. Synthesis of typization and invention is interpretation. Interpretation in Alexander's understanding is something more than a purely intellectual effort. Every action in the world is an interpretation of reality (Alexander, 1988, p. 314).

It is action that allows actors to move in time and space. Every action contains a dimension of free will or agency (Alexander, 1998, p. 215). 
Structure does not exclude free will and autonomy of individuals, although it points to their limits (freedom is never total and unconditioned); all the less it diminishes social actors' sense of liberty and agency. Agency is the moment of freedom, which occurs in three structured environments: personality, society and culture, whereby personality and culture exist exclusively inside the actors (Alexander, 1998, p. 215). Ability to take action based on knowledge does not emerge from nowhere, but derives from the society and from the "cultural milieu" in which the actors live and in which their identity has been shaped; their knowledge is social in character, and their actions, motivated by personality, are featured by cultural systems and codes. "Culture and personality are themselves social structures" (Alexander, 1998 , p. 216). We can describe them as existing outside the actors, if we chose to focus on the social system, but we can also describe them in more philosophical terms, as an expression of personal liberty or of uniqueness proper to individual existence. Culture is at the same time an inner and an external world (environment) of each and every actor. Understanding social reality, we cannot prescind from how individuals that form a given society understand themselves, their actions, their interactions with others, from how they understand the world they live in. Reflecting on social life we assume, however, that individuals have neither full knowledge about their situation nor full understanding of the world. Because human actions have determined meanings, they can and should be interpreted just like texts. In this way Alexander turns towards Paul Ricoeur's hermeneutics, launching a project of structural hermeneutics that becomes the point of departure for his strong program of cultural sociology.

"We are not anywhere as reasonable or rational or sensible as we would like to think" - writes Alexander. "We still lead lives dictated more by unconscious than conscious reason. We are still compelled by feelings of the heart and the fearful instincts of the gut" (Alexander, 2003, p. 3). Rhetorical figures that we use justifying our choices and actions are nothing other than cultural structures. Constant elements of the repertoire of our narrations are references to such issues and good and evil, friendship and hostility, God, honor, conscience, loyalty, fatherland. These are figures of collective imagination, carrying a huge emotional charge. "The secret to the compulsive power of social structures is that they have an inside. They are not only external to actors but internal to them. They are meaningful" (Alexander, 2003, p. 4). These meanings are produced socially. Cultural sociology constitutes, 
according to Alexander, a kind of social psychoanalysis (in the same way Bourdieu referred to his reflection), ${ }^{2}$ whose objective is to lighten the dark shadows of collective unconsciousness, to penetrate the myths shaping our way of thinking and to interpret collective meanings and ways of their influence. Socially constructed subjectivity becomes collective will, featuring rules of social life and defining the moral essence of the law, delivering meanings and motivations to all areas of social life. The task of social theory is to "build maps of complex symbolic codes. They show how the fates of individuals, groups and nations are often determined by these invisible but often gigantically powerful and patterned ideational rays" (Alexander, 2003, p. 7). Let us notice that these rays do not reach us from ahistorical, ideal space, but from the past, that sediments and continues to live in our collective memory. The present shape and form of our society does not depend solely and uniquely on economic and/or political factors, not only and not above all on constant pursuit of profit, on greed for power, domination and prestige, not only and not chiefly on administrational techniques. It depends instead on the culture of a given society, on the culture that is its memory.

\section{Further perspectives}

Having shown, as I presume, rather visibly the connection between social frames of memory and the social structure in considerations of the above mentioned authors, I will now proceed to pose the question about a certain specific aspect of the social reality that reveals itself in these analyses. Studying them closely we may say that the question concerning the relation of the process of shaping the social structure (Bourdieu), of social change (Touraine) or of structuration (Giddens) to social structure as a certain static datum is a long-standing problem in sociology. Posing this question in an abstract way and repeating it here would be all too ambitious and, as I think, idle and fruitless. Yet the specific theoretical asset, educed by juxtaposition of the problematic of structuration and constitution of society with

2 Cf. Alexander's crucial and programmatic statement: "Cultural sociology is a kind of social psychoanalysis. Its goal is to bring the social unconscious up for view. To reveal to men and women the myths that think them so that they can make new myths in turn" (Alexander. 2003, p. 4; cf. also Bourdieu, Wacquant, 1992a, p. 63). 
the problematic of memory, seems to be the possibility of a closer description of the way in which structuration passes into structure, in which the flowing process of emerging stratification and social order, the process of formation of functions, of acquiring the right to possess certain dispositions and distinguishing qualities, passes into an established, durable and static structure and social hierarchy, in an established order that nobody - at least for a certain period of time - dares to question.

It is this aspect that appears to be particularly interesting. Even if at a certain stage of history of society - as we mentioned, referring to Halbwachs - comes to the fore a procedural and formalistic attitude of mind, an attitude that does not care about history and does not look for depth, focusing on efficiency of current action (such an attitude can be rightly associated with modernity and its semantic universe), even then this procedural formalism will depend on mnemologically analizable depth, because this very procedural formalism itself, existing in a certain determined form, is a result of a certain historical process. What is of paramount importance here do not seem to be existing hierarchies of values, competences and titles - they appear to be only ready-made products - but rather that what, following Halbwachs, we may refer to as "the constant effort of maintaining a specific spiritual attitude". In the meaning determined by the German notion of Geist - where "the spirit" means inner attitude as well as the whole external domain of culture and humanities - such a spiritual attitude is the object of study that the interpretation of social frames of memory attempts to inquire.

It is then high time to investigate - without falling into the autopoietic exaggeration that may be suspected in Touraine, and without emphasizing in a Sartrean way the absolute autonomy of self-constructing collective social subject who, oblivious of the past, projects its imagined destiny into the future - it is, I would say, about time to deliberate how emerges the social space described by Bourdieu, generating sequences of distinctions, fields and capitals. If indeed - as suggest analyses of the contemporary French society presented by Bourdieu - academic titles are historical descendants of noble titles, perpetuating the preexistent ordre établi, then it is appropriate to ask how did this happen and how much we had to forget from the complex history of social privileges to make them effectively function in today's world. The relation existing between learning abilities and cultural capital, problematized by Bourdieu, belongs to the domain of memory; sedimentation 
and reproduction of structures that we encounter in Giddens's analyses is function of social memory. Asking about memory, we reach in fact not only into a certain social imaginarium, into the realm of emotions and dreams, bearing the well-known order, but actually much deeper - as Giddens suggests, pointing to the three levels of knowledge, into the somber and obscure, dangerous and unknown realm of the unconscious. It is only then that the given, preestablished structure can reveal itself to us as a "virtual order of transformative relations", graspable in statu nascendi. Assuming such a perspective, we agree, however, to develop a sui generis "social psychoanalysis" (Bourdieu, Alexander) - and thus we enter into an unknown territory, where neither concepts nor methods have been yet elaborated.

Together with Assmann we ask about the possibility of inner integration of communities, about the history of distinctiveness, elitism, writing, systems and orders of signs. Following this path, we treat social structure as a trace of memory, more in Derridean terms, sending us back to a sort of khora, where everything bears and is born. Systems of signs and ways of their deciphering reveal themselves to us as traces of difficult struggles for order and identity. Who knows what can be more useful in these considerations as a signpost? Apart from all the themes of universal history of culture, such as the history of ancient Egipt (Assmann), of prerevolutionary bourgeoisie (Halbwachs) or distinctions of the contemporary French society (Bourdieu) we encounter on the Polish ground, as one of the possible examples of the forgotten, the dramatic history of unreliable acquisition of nobility titles, known thanks to the 17. century treaty Liber chamorum by a certain Walerian Nekanda Trepka. This forgotten genesis of aristocratic dignity, awash with tears, infamy and disgrace, immersed in morass of human fate, mired in odiousness of human avarice and in atrocity of slander, turns out to be the "first [Polish] vernacular sociological essay concerning the inter-estate advancement in the 17. century" (Kruk-Siwiec, 2017, p. 423; see also Szacki, 1964, p. 4). In order to attain the necessary positive view on the misery of history, we need, however, the ability of benevolent interpretation, of accurate and impartial extraction of the typization process, the ability that will allow us to accept with gracious serenity the fact that, constructing and structuring society, we are "compelled by feelings of the heart and the fearful instincts of the gut". I presume that the analyses of Jeffrey Alexander's social theory are particularly promising in this regard. 


\section{References}

Alexander, J. (1988). Action and Its Environments. In: idem, Action and Its Environments. Towards a New Synthesis (pp. 301-334). New York: Columbia University Press.

Alexander, J. (1998). After Neofunctionalism. Action, Culture, and Civil Society. In: idem, Neofunctionalism and After (pp. 210-233). Oxford: Blackwell.

Alexander, J. (2003). The Meanings of (Social) Life. On the Origins of a Cultural Sociology. In: idem, The Meanings of Social Life. A Cultural Sociology (pp. 3-10). Oxford: Oxford University Press.

Assmann, J. (2011). Cultural Memory and Early Civilization. Writing, Rememberance, and Political Imagination. Cambridge: Cambridge University Press.

Bourdieu, P. (1998). Practical Reason. On the Theory of Action. Stanford: Stanford University Press.

Bourdieu, P., Wacquant, L.D.J. (1992a). Sociology as Socioanalysis. In: eidem, An Invitation to Reflexive Sociology (pp. 62-74). Cambridge: Polity Press.

Bourdieu, P., Wacquant, L.D.J. (1992b). The Unique and the Invariant. In: eidem, An Invitation to Reflexive Sociology (pp. 75-94). Cambridge: Polity Press.

Castoriadis, C. (1987). The Imaginary Institution of Society. Cambridge: Polity Press.

Giddens, A. (1984). The Constitution of Society. Outline of the Theory of Structuration. Cambridge: Polity Press.

Halbwachs, M. (1992). On Collective Memory. Chicago: The University of Chicago Press.

Kruk-Siwiec, J. (2017). O niejednoznaczności gatunkowej Liber chamorum Waleriana Nekandy Trepki [On the genre equivocality of Walerian Nekanda Trepka's Liber chamorum]. In: T. Nastulczyk, S. Siess-Krzyszkowski (eds.), Nihil sine litteris. Scripta in honorem professoris Venceslai Walecki (pp. 409-423). Krakow: Wydawnictwo Uniwersytetu Jagiellońskiego.

Szacki, J. (1964). Chłopus szlachcicem. Nowe Ksiażki, 1, 3.

Touraine, A. (1977). Historicity. In: idem, The Self-Production of Society (pp. 15-64). Chicago-London: The University of Chicago Press. 


\section{SOCIAL STRUCTURE AND COLLECTIVE MEMORY}

\section{Summary}

The paper explores the relation between collective memory and social theory, trying in particular to show the key role that the notion of collective memory plays in understanding the dynamics of the social process (structuration, genesis of social structure). It does it by means of a series of reinterpretations of classical authors. Investigating the phenomenon of forgetting as covering up the traces of social change (M. Halbwachs), problematized in the contemporary context (P. Bourdieu), leads us to unraveling the problematic character of social change as such in a vain effort of annulment of memory (A. Touraine), and finally to rediscovering of social memory at a deeper level, as a profound structure of social processes. This discovery points to the necessity of introducing a new, yet undeveloped method of studying the social unconscious (A. Giddens, J. Assmann, and in particular J. Alexander). Jeffrey Alexander overtly postulates such a development, identifying his major project of cultural sociology with a kind of social psychoanalysis. The paper ends with a question - where such a postulate leads us to? Perhaps we need a new kind of art of benevolent interpretation that brings along with new understanding also some kind of soothing the pain of misery, deeply inscribed in social existence. 